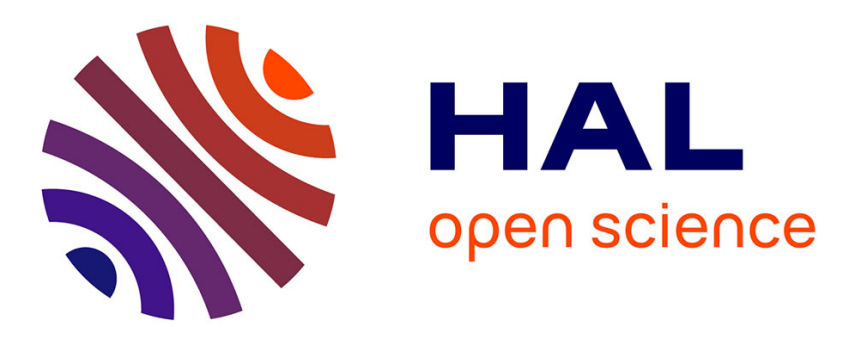

\title{
The story of the moment: Risk averse Cypriot farmers respond to drought management
}

\author{
Alban Thomas, Ben Groom, Phoebe Koundouri, Celine Nauges
}

\section{To cite this version:}

Alban Thomas, Ben Groom, Phoebe Koundouri, Celine Nauges. The story of the moment: Risk averse Cypriot farmers respond to drought management. Applied Economics, 2008, 40 (03), pp.315326. 10.1080/00036840600592916 . hal-00581984

\section{HAL Id: hal-00581984 \\ https://hal.science/hal-00581984}

Submitted on 1 Apr 2011

HAL is a multi-disciplinary open access archive for the deposit and dissemination of scientific research documents, whether they are published or not. The documents may come from teaching and research institutions in France or abroad, or from public or private research centers.
L'archive ouverte pluridisciplinaire HAL, est destinée au dépôt et à la diffusion de documents scientifiques de niveau recherche, publiés ou non, émanant des établissements d'enseignement et de recherche français ou étrangers, des laboratoires publics ou privés. 


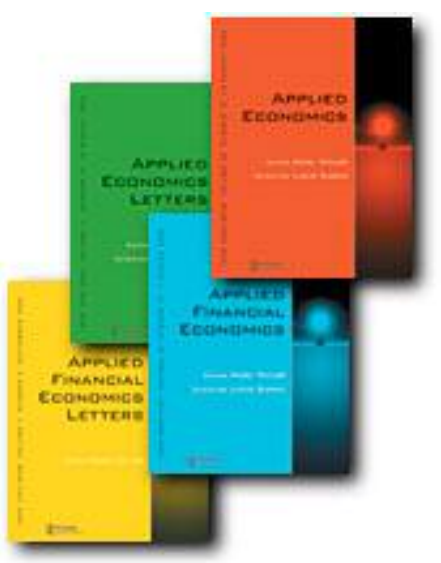

The story of the moment: Risk averse Cypriot farmers respond to drought management

\begin{tabular}{|c|c|}
\hline Journal: & Applied Economics \\
\hline Manuscript ID: & APE-05-0489.R1 \\
\hline Journal Selection: & Applied Economics \\
\hline $\begin{array}{r}\text { Date Submitted by the } \\
\text { Author: }\end{array}$ & 16-Jan-2006 \\
\hline JEL Code: & $\begin{array}{l}\text { Q12 - Micro Analysis of Farm Firms, Farm Households, and Farm } \\
\text { Input Markets }<\text { Q1 - Agriculture }<\mathrm{Q}-\text { Agricultural and Natural } \\
\text { Resource Economics, Q38 - Government Policy }<\text { Q3 - } \\
\text { Nonrenewable Resources and Conservation }<\mathrm{Q}-\text { Agricultural and } \\
\text { Natural Resource Economics, Q25 - Water }<\mathrm{Q} 2 \text { - Renewable } \\
\text { Resources and Conservation|Environmental Management }<\mathrm{Q} \text { - } \\
\text { Agricultural and Natural Resource Economics }\end{array}$ \\
\hline Keywords: & $\begin{array}{l}\text { risk attitudes, stochastic agricultural production, moment-based } \\
\text { estimation, conservation policy }\end{array}$ \\
\hline
\end{tabular}

\section{Manuscript Central ${ }^{\text {TH}}$}




\title{
The Story of the Moment: \\ Risk Averse Cypriot Farmers Respond to Drought Management
}

\author{
Ben Groom ${ }^{\dagger}$, Phoebe Koundouri ${ }^{\ddagger}$, Céline Nauges* and Alban Thomas*
}

This version, January 15, 2006

\begin{abstract}
This paper illustrates the importance of estimating risk preferences when evaluating water policy. Using agricultural production data from the Kiti region of Cyprus we estimate farmers' risk preferences à la Antle $(1983,1987)$ and show sensitivity to higher order moments of profit, such as skewness. We show that farmers in the Kiti region are risk averse with risk premiums in the region of $20 \%$ of expected profit. We use these estimates to analyse the impact of a water quota from the perspective of three policy-makers who differ only in their understanding of farmers' risk preferences. We show in the case of Kiti that policymakers who model risk preferences incorrectly, that is, either; a) assume risk neutrality or; b) ignore down-side risk, wrongly predict the magnitude and direction of input responses and therefore the magnitude of welfare changes. This highlights the importance of accommodating preferences for higher order moments of profit in the evaluation of water policy.
\end{abstract}

Keywords: stochastic agricultural production, risk attitudes, conservation policy, momentsbased estimation.

\footnotetext{
† Department of Economics, School of Oriental and African Studies, University of London.

‡ Department of International and European Economic Studies, Athens University of Economics and Business and Department of Economics, University College London.

* INRA-LERNA, University of Toulouse.
} 


\section{The Story of the Moment:}

\section{Risk Averse Cypriot Farmers Respond to Drought Management}

\section{Introduction}

In recent years much attention has been paid to the analysis of farmers' responses to water conservation policies (e.g. Moore et al., 1994; Schaible, 1997; Iglesias et al., 2003). Naturally, irrigated agriculture has been the focus of much of this analysis due to the common perception of this sector as both 'originator and victim' of drought (Grigg, 1996, Iglesias et al., 2003). Several key dimensions of farmer responses to water conservation policies, such as water pricing or quantitative restrictions, have been studied empirically. For instance, the price elasticity of demand for irrigation water (e.g., Nieswiadomy, 1988); the effect of water price on irrigation development and irrigation technology choice, (e.g., Koundouri et al., 2005); the effect of water restrictions and pricing on crop-choice, land allocation, and crop specific water demand (e.g., Moore et al., 1994, Moore and Negri, 1992). More recently, Schaible (1997) analysed farmers' responses to water conservation policies where groundwater is available as a substitute, while Keplinger et al. (1998) focus on quantitative restrictions on groundwater use. Furthermore, using a dynamic simulation, Iglesias et al. (2003) show that prudent surface water allocations during non-drought years can limit the negative impacts of water quantity restrictions upon farmers during periods of drought.

Despite this burgeoning literature, one dimension of farmers' responses that is frequently overlooked in the evaluation of water conservation policies is farmers' preference for risk. This is likely to be a serious omission since, not only is uncertainty almost ubiquitous for farmers, e.g. due to climatic variability and the prospect of drought, but production theory and empirical evidence shows clearly that farmers' preferences for risk are of considerable moment in determining their production decisions (e.g. Leathers and Quiggin 1991, Wik et al. 2004, Miyata 2003). Hence, to a large extent, risk preferences will determine responses to, and the welfare impacts of, water conservation policies ${ }^{\mathrm{i}}$.

Unfortunately, the empirical problems associated with incorporating risk in production analysis are numerous. Early empirical studies made implicit, if not explicit assumptions regarding the effect of inputs on production risk ${ }^{\text {ii }}$. The multiplicative stochastic specifications 
employed disallowed inputs that marginally reduce risk. Such models are clearly at odds with the risk-reducing nature of some inputs and the observation that risk averse farmers configure their inputs to hedge against production risk in line with their risk preferences. As an initial response, Just and Pope $(1978,1979)$ (JP) proposed a more general stochastic specification for the production function allowing risk-increasing or risk-decreasing inputs. However, Antle (1983, 1987) showed that JP restricts the effects of inputs across higher order moments in exactly the way traditional econometric models do across all moments. Antle's 'momentbased approach' identified a set of general conditions under which standard econometric techniques can be used to identify agricultural technology without imposing such arbitrary restrictions on inputs.

One further advantage of Antle's method is that, while later contributions (e.g. Love and Buccola, 1991, 1999) could not escape making implicit assumptions about the form of farmers' utility functions ${ }^{\mathrm{iii}}$, Antle (1987), and more recently Kumbhakar (2002), also provides a flexible approach to the estimation of risk preferences. In each case risk preferences are estimated as part of a structural econometric model in which neither the impact of inputs on risk nor the form of the utility function is restricted. These qualities make the approach ideally suited to analyse responses to interventions in uncertain environments.

In the light of this discussion, the objectives of this paper are twofold. Firstly, we wish to understand precisely how farmers' decisions are influenced by their risk preferences. Secondly, we wish to establish the importance of considering risk preferences in the ex ante evaluation of the welfare impacts of temporary water conservation policies. Such temporary restrictions are frequently implemented in response to severe and unexpected drought and are commonplace in irrigation water management in general (Iglesias et al. 2003). Less common however, is any analysis either of how preferences over higher order moments of profit determine farmers' responses or, more importantly, the potential costs of ignoring these determinants in the evaluation process.

We use production data from the Kiti region of Cyprus. Kiti is representative of arid and semi-arid agricultural regions in that considerable climatic uncertainty prevails, while it reflects our policy interests in that water restrictions are employed periodically and at short notice here in response to drought episodes (Socratous, 2000; Koundouri, 2000). In meeting 
our first objective we employ Antle's $(1983,1987)$ moment based approach to flexibly estimate agricultural technology and risk preferences reflected by Arrow-Pratt and down-side measures, as well as risk premiums. Towards our second objective we use the empirical estimates to evaluate farmers' responses to, and welfare impacts of, the imposition of an irrigation water quota. We contrast the evaluations of three hypothetical water managers that differ only in the extent to which they have information on farmers' risk preferences. This analysis reveals how the determination of water restrictions, predicted input responses and the design of drought compensation policies, may differ in light of information about such preferences.

The paper is organised as follows. In the Section 2, we present the underlying model of farmer behaviour under risk and discuss implications of risk aversion for simple conservation policies (irrigation water quota). The data are described in Section 3. Section 4 presents the econometric analysis and results. Section 5 presents the policy analysis for our hypothetical water planners. Section 6 concludes.

\section{Farmer behaviour under risk: the response to water restrictions}

In this section we analyse the impact of drought management policy on the production decisions of a farmer in a risky environment. To fix ideas we assume that the source of production risk is climatic and that the drought management policy is a temporary restriction upon water use: a water quota. Given the temporary nature of the water quota, our focus here is on variable inputs in agricultural production, such as water, fertilizers, and labour, whose choice and mixture may be modified by the farmer in the short-run in order to hedge against production risk. Furthermore, given the temporary nature of the quota, land allocation decisions and their relationship with variable-input demand are not addressed here. I.e., land is assumed to be a fixed factor and does not respond to temporary drought management policies. This means that fixed cost and technology choice considerations are also outside the scope of this paper. We assume throughout that technology is fixed and known to the environmental regulator. As for prices, we make the assumption that farmers are price-takers, so that a modification in their input allocation decision following, e.g., the implementation of the water quota, will affect neither output nor input prices. Finally prices are perfectly predictable in the short-run, so that they are considered non-random by the farmer ${ }^{\mathrm{iv}}$. 
Assume the environmental agency selects a value for the water quota in order to maximize a social welfare objective criterion including environmental considerations. Such welfare function would typically include the consumer surplus associated with the good produced, any environmental externalities related to natural resource depletion, and so on. An important aspect of our framework is that the quota is exogenous, so that once it is chosen, farmers decide on their production plans considering this quota as given. Both problems (choice of quota conservation policy and decision on the level of production) are thus completely separated. This can be thought of as a scenario in which the agency's environmental criterion is based upon the whole population of farmers, e.g. through some technological and preference representation, and each farmer is too small to influence the agency's decision. A key ingredient to assess accurately the performance of such conservation policy is naturally the sensitivity of producers to different values of the quota (the conservation policy instrument). This requires first, an adequate representation of the technology, but also of farmer preferences towards risk.

\section{The model of production}

In this section, the basic representative agent production model under risk is developed. As noted above, we assume an exogenously given quota whose determination is not detailed here. Let $p$ denote output price for a single crop, $f($.$) is the production function, \boldsymbol{X}$ is the $\mathrm{K}$ vector of inputs, and $\boldsymbol{r}$ is the corresponding vector of unit input prices. The environmental policy quota is directed towards a single input, irrigation water in our case, which is denoted $X_{w}$ with associated unit price $r_{w}$. We then have $\mathbf{X}^{\prime}=\left(X_{1}, X_{2}, \ldots, X_{K-1}, X_{w}\right)$ and $\mathbf{r}^{\prime}=\left(r_{1}, r_{2}, \ldots, r_{K-1}, r_{w}\right)$. The restriction imposed on $X_{w}$ is written ${ }^{\mathrm{v}}$ :

$X_{w} \leq \bar{X}_{w}$

We assume that climatic risk affects crop yield through the variable $\varepsilon$, whose distribution $G($.$) is not affected by farmer actions. In addition, to fix ideas we assume that prices p$ and $\boldsymbol{r}$ are non-random, so that $\varepsilon$ is the only source of production risk ${ }^{\mathrm{vi}}$. Let us suppose further that $f($.$) is continuous and twice differentiable. The agent's problem is to maximize expected$ profit if she is risk-neutral, or to maximize the expected utility of profit if she is risk-averse, subject to condition [1]. In the latter case, the agent's problem is 
$\operatorname{Max}_{\mathbf{X}} \mathrm{E}[U(\pi)]=\operatorname{Max}_{\mathbf{X}} \int\left[U\left(p f(\varepsilon, \mathbf{X})-\mathbf{r}^{\prime} \mathbf{X}\right)\right] d G(\varepsilon)+\lambda\left(\bar{X}_{w}-X_{w}\right)$,

where $U($.$) is the Von Neuman-Morgenstern utility function and \lambda$ is the Lagrange multiplier associated with [1]. The optimal solution for element $X_{k}$ would then depend upon $(p, \mathbf{r})$ and on the shape of functions $U(),. f($.$) and G($.$) . The first-order condition for irrigation water$ input, $X_{w}$, associated with this problem is:

$$
\begin{aligned}
& \mathrm{E}\left[r_{\mathrm{w}} \times U^{\prime}\right]=\mathrm{E}\left[p \frac{\partial f(\varepsilon, \mathbf{X})}{\partial X_{\mathrm{w}}} \times U^{\prime}\right]-\lambda \\
& \Leftrightarrow \frac{r_{w}+\lambda / \mathrm{E}\left(U^{\prime}\right)}{p}=E\left(\frac{\partial f(\varepsilon, \mathbf{X})}{\partial X_{w}}\right)+\frac{\operatorname{cov}\left(U^{\prime}, \partial f(\varepsilon, \mathbf{X}) / \partial X_{\mathrm{w}}\right)}{\mathrm{E}\left(U^{\prime}\right)}
\end{aligned}
$$

because $p$ and the volumetric price of irrigation water, $r_{w}$, are not random, and where $U^{\prime}=\partial U(\pi) / \partial \pi$. It is apparent that the shape of the utility function (whose curvature is increasing with the degree of absolute risk aversion) will determine the magnitude of the departure from the risk-neutrality case. For a risk-neutral producer, the price ratio under the quota $(1 / p)\left[r_{w}+\lambda / \mathrm{E}\left(U^{\prime}\right)\right]$ equals the expected marginal productivity of $X_{w}$. When the producer is risk averse, the second term in the right-hand side of [3] is different from 0 , and measures deviations from the risk-neutrality case. More precisely, this term is proportional and has the opposite sign, to the marginal risk premium. If irrigation water is risk increasing, the marginal risk premium increases with $X_{w}$ and the desired level of that input decreases, all other things being equal. In principle, solving Equation [3] for $X_{w}$ yields the equilibrium input quantity in terms of $p, r, \bar{X}_{w}$ and $\lambda$.

This problem, however, is empirically difficult. In addition to the choice of technology specification, the distribution of $\varepsilon$ needs to be known and the agent's preferences need to be specified. For this reason we choose a flexible estimation approach that has the advantage of requiring only cross-sectional information on prices and input quantities. The key feature of 
this approach is to note that the solution to the producer problem can be written as a function of input levels alone. More precisely, maximizing the expected utility of profit under the quota restriction with respect to any input, is equivalent to maximizing a function of moments of the distribution of $\varepsilon$, those moments having themselves $\boldsymbol{X}$ as an argument. There is no loss of generality here, because such a function of the moments, denoted $F($.$) , is completely$ unspecified. The farmer's problem becomes:

$$
\operatorname{Max}_{\mathbf{X}} \mathrm{E}[U(\pi)]=F\left[\mu_{1}(\mathbf{X}), \mu_{2}(\mathbf{X}), \ldots, \mu_{m}(\mathbf{X})\right] \text { subject to } X_{w} \leq \bar{X}_{w}
$$

where $\mu_{j}=E\left(\Pi-\mu_{1}\right)^{j}, j=2, \ldots, m$, is the $m^{\text {th }}$ moment of profit.

\section{Assessing risk attitudes: Antle's approach}

Based on the expression above, Antle (1983, 1987) proposes a moment-based approach to estimate risk-attitude parameters of a population of producers. Focusing on the population instead of focusing on each individual producer has two main advantages. It avoids any problem of aggregation of individuals and allows the identification of the riskattitude parameters from a cross-sectional dataset. However, this approach relies on some assumptions. First, the farmer solves a single-period maximisation program in which inputs are predetermined variables. Second, all farmers produce with similar technology. Below, this stochastic technology is represented by the corresponding distribution of profit, which amounts to assuming that the same profit distribution applies to each farm and that all farmers form the same expectations.

Antle's method amounts to estimating the following $K$ equations, which are derived from the first order condition for the $k^{\text {th }}$ input $(k=1, \ldots, K)$ in matrix form:

$$
\frac{\partial \mu_{1}(X)}{\partial X_{k}}=\theta_{1 k}+\theta_{2 k} \frac{\partial \mu_{2}(X)}{\partial X_{k}}+\theta_{3 k} \frac{\partial \mu_{3}(X)}{\partial X_{k}}+\cdots+\theta_{m k} \frac{\partial \mu_{m}(X)}{\partial X_{k}}+u_{k}
$$

where $\theta_{j k}(j=2, \ldots, m)$ is equal to $-1 / j ! \times\left(\partial F(\mathbf{X}) / \partial \mu_{j}(\mathbf{X})\right) /\left(\partial F(\mathbf{X}) / \partial \mu_{1}(\mathbf{X})\right)$; that is, $\theta_{j k}$ represents average population risk attitude parameter relating to the $j^{\text {th }}$ moment in the $k^{\text {th }}$ 
input's first order condition. Hence for each input $k$, we have $m$ unknown parameters, $\theta_{j k}$, and $u_{k}$ is the usual econometric error term ${ }^{\text {vii }}$.

The analysis is made input by input to capture the possibility that each input contributes differently to the moments of the profit distribution. In general, we expect that all inputs increase the expected profit but, for the second-order moment, inputs can be risk-increasing or risk-decreasing. Equation [5] shows that the marginal contribution of input $k$ to the expected profit, given by $\partial \mu_{1}(X) / \partial X_{k}$, is written as a linear combination of the marginal contributions of input $k$ to the other moments (variance: $\partial \mu_{2}(X) / \partial X_{k}$, skewness: $\left.\partial \mu_{3}(X) / \partial X_{k}, \ldots\right)$. The most important feature of this model is that the parameters $\theta_{2 k}$ and $\theta_{3 k}$ are directly interpretable as Arrow-Pratt and down-side risk aversion coefficients, respectively. The Arrow-Pratt $(A P)$ absolute risk aversion coefficient is defined by:

$$
A P=-\frac{E\left(U^{\prime \prime}(\pi)\right)}{E\left(U^{\prime}(\pi)\right)} \cong-\frac{\partial F(X) / \partial \mu_{2}(X)}{\partial F(X) / \partial \mu_{1}(X)}=2 \theta_{2}
$$

A positive $A P$ coefficient means that the farmer is risk-averse. Down-side (DS) risk aversion is measured by:

$$
D S=\frac{E\left(U^{\prime \prime \prime}(\pi)\right)}{E\left(U^{\prime}(\pi)\right)} \cong \frac{\partial F(X) / \partial \mu_{3}(X)}{\partial F(X) / \partial \mu_{1}(X)}=-6 \theta_{3} .
$$

A positive DS coefficient means that the farmer is averse to down-side risk, where downside-risk aversion can be thought of as a preference for disaster avoidance ${ }^{\text {viii }}$. It is important to notice that in [6] and [7] we have dropped the index $k$. This reflects that, contrary to Antle (1987), we take the view that it does not make sense to have input specific measures of risk aversion. Although each input can affect the moments of profit in different ways, the $A P$ and $D S$ coefficients are related to the preferences over the moments of profit, $\Pi$. For this reason, no matter what the effect of inputs on the moments of profit, the preferences over moments of profit should remain the same across inputs. Thus it should be the case that $\theta_{j k}=\theta_{j}$, and hence $A P_{k}=A P$ and $D S_{k}=D S$. 
The $A P$ and $D S$ coefficients can then be used to compute the risk premium, denoted $R P$. Assuming that the farmer is concerned by the first three moments of the distribution only, we have $R P=\mu_{2} A P / 2-\mu_{3} D S / 6$, where $\mu_{2}$ and $\mu_{3}$ are respectively a measure of the secondand third-order moments of the distribution. $R P>0$ means that the farmer is characterized by a positive willingness-to-pay to be insured against risk. Coefficients $\theta_{2}$ and $\theta_{3}$, directly related to $A P$ and $D S$, can also be interpreted as a measure of the marginal contribution of each moment to the risk premium.

\section{Dataset description}

Cyprus is representative of arid and semi-arid regions in general, typified by low and variable rainfall and overuse of groundwater resources. There are a wide variety of crops grown in Cyprus ranging from the permanent crops such as olives, citrus and other deciduous fruits and nuts, to more temporary cereal and vegetable crops. The Kiti region lies within the southerly Larnaca area of Government controlled Cyprus. To date over 2200ha of irrigation has been developed in the Larnaca area (MIT, 1999) and historically the Kiti region has been dependent upon groundwater to sustain irrigated agriculture.

The farm level data is drawn from a survey of agricultural production of the coastal Kiti region of Cyprus undertaken by the University of Cyprus and the Ministry of Agriculture in the summer of 1998. A cross-section of 283 farmers was surveyed regarding production activities on representative parcels of their land. Information included expenditures upon, and quantities purchased of, fixed and variable inputs used in the production of final outputs. The total area of land owned by the farmer and the area(s) devoted to irrigated/non-irrigated and temporary/permanent crops were also provided. The survey data included climatic data in the form of rainfall measurements and soil quality characteristics for each parcel of land. Qualitative data was also provided, e.g. information regarding farm ownership, family characteristics and access to water resources. The total area of land cultivated by the farmers is 807 ha of which approximately $42 \%$ is irrigated. The cross-section sample represents approximately $15 \%$ of the developed irrigated land in the Larnaca area ${ }^{\mathrm{ix}}$. The wide variety of crop types represented in the sample necessitated the grouping of crops into broad categories to overcome the sparseness of individual crop observations ${ }^{\mathrm{x}}$. Crops have been grouped into two categories namely: vegetables and cereals ${ }^{\mathrm{xi}}$. Once grouped in this way, the data show that 
$85 \%$ of the farmers grow a single crop. The data sample used is almost equally dominated by agricultural parcels, which cultivate vegetables (133 parcels) and cereals (135 parcels). Relatively few agricultural units choose to cultivate citrus (30 parcels). Moreover, on average more hectares per parcel of land are devoted to vegetables (2.87) and cereals (2.79) cultivations, than to citrus cultivations. While mean annual crop-specific gross revenues (total sales) per hectare of land are higher for vegetables than for cereals, vegetable cultivation involves higher mean input expenditure. The variability of expenditures among farmers is also higher for vegetables. Table 1 presents descriptive statistics by crop groups regarding surface, revenue and major input expenditures. We also report descriptive statistics for variables to be used as instruments in the econometric application: WELLON, a dummy variable which takes the value of 1 if there is a well in the parcel and zero otherwise, DIST1: distance of the parcel to the nearest town (in km), DIST5: distance of the parcel to the nearest river (in $\mathrm{km}$ ), RESERVOIR, a dummy variable which takes the value of 1 if the farmer has access to a water reservoir and zero otherwise, LAND, a dummy variable which takes the value of 1 if the parcel belongs to an agricultural zone and zero otherwise.

\section{[Table 1 here]}

Data on the quantities of water used in crop production were sparse. In response, information regarding water requirements for the specified crops were gathered from the Ministry of Agriculture (Agricultural Research Institute, 1998) and were used to calculate theoretical water demands for the farms based on the areas of land devoted to particular crops. This information is used in the absence of specific data on irrigation water use $\mathrm{e}^{\mathrm{xii}}$. Similarly, data regarding the cost of water were sparse. This necessitated the construction of a tariff for groundwater pumping costs based on hydrological information obtained from the Ministry of Agriculture in Nicosia ${ }^{\text {xiii }}$. It is assumed here that farms are totally reliant on groundwater, an assumption again borne out by the data, which shows that $80 \%$ of the farmers use solely groundwater in this area.

\section{Econometric estimation and results}

\section{Estimation}

Following Antle (1987), we propose to estimate the sample-average risk-attitude parameters. Given that $85 \%$ of the farmers grow a single crop, we distinguish between two 
groups of producers: producers of vegetables and cereals. We report the results for three important variable inputs: fertiliser (including manure), agricultural labour and water. For both groups, our estimation methodology is the following. First, we estimate the conditional expectation of profit using a quadratic functional form: total observed profit is regressed on all levels, squared and cross-products of input expenditures ${ }^{\mathrm{xiv}}$. We choose a linear quadratic form because it is flexible in the sense of a second-order approximation of any unknown profit function (Kumbhakar and Tveterås, 2003). The residuals of the latter regression are then used to compute conditional higher moments (variance and skewness) and are regressed on all levels, squared and cross-products of input expenditures ${ }^{\mathrm{xv}}$.

Analytical expressions for derivatives of these moments with respect to each input are then computed. Finally, we use 2SLS (Two-Stage Least Squares) to estimate the system of equations [5] above for three inputs, water, labour and fertiliser. Instruments used were (WELLON, DIST1, DIST5 RESERVOIR, LAND), see above for a definition and Table 1 for summary statistics on these variables. These instruments are the same for each equation (fertiliser, water, labour), in the case of cereals as well as vegetables.

However, as discussed in the previous section, contrary to the work of Antle (1987) and in line with economic theory, we restrict the coefficients upon the moments of profit to be equal across inputs, i.e. we estimate the system in [5] with the following restrictions: $\hat{\theta}_{2 k}=\hat{\theta}_{2}$ and $\hat{\theta}_{3 k}=\hat{\theta}_{3}$, where $k=$ fertiliser, labour, water. The estimated parameters are then used to recover the population average Arrow-Pratt $(A P)$ and down-side $(D S)$ risk aversion measures using the relationships in [6] and [7]: $A P \cong 2 \hat{\theta}_{2}$ and $D S \cong-6 \hat{\theta}_{3}$. These estimates are finally used to compute the risk premium, $R P$, which is approximately equal to:

$$
R P \cong \frac{1}{2} \mu_{2} A P-\frac{1}{6} \mu_{3} D S
$$

where $\mu_{2}$ and $\mu_{3}$ are as before: measures of the second and third moments of profit. The estimation is undertaken for two crop-groups: cereals and vegetables, and hence crop specific risk aversion parameters are estimated. This is not to say that risk aversion varies across crops for a given farmer, but rather to capture the observation made earlier that these crop groups 
are grown by different groups of farmers in our sample. Hence, the average risk aversion coefficients are likely to differ between crops.

The results also allow us to estimate the elasticity of the various moments of profit with respect to inputs. This provides us with some indication of the extent to which inputs are risk increasing or decreasing in the production of each crop. In turn, in the following section this enables us to understand how restricted water allocations affect the welfare of risk averse farmers. The results of estimation procedure: the population average risk aversion parameters, test statistics and elasticities of profit moments are reported in Tables 2 and 3 below.

\section{Results}

The estimates in Table 2 show that the farmers in the Kiti area exhibit positive Arrow Pratt and downside risk aversion parameters. This indicates that on average cereal and vegetable farmers in the Kiti region of Cyprus have preferences over higher order moments of profit since they are averse to risk (profit variance) and down-side risk (profit skewness).

\section{[Table 2 here]}

Furthermore it is interesting to note that the extent of risk aversion appears to be different for cereal farmers compared to vegetable farmers. This is indicated by the higher estimate for $A P$ in the cereal group, while DS parameter is not significant in the latter but significant for vegetable farmers. The Wald test statistic for equality between $A P$ and $D S$ parameters across the two groups is equal to 264.98, with an associated p-value less than 0.0001 . Hence, the hypothesis of similar risk preferences for cereal and vegetable producers is strongly rejected and the following two results are established: (a) cereal farmers are willing to give up more of their expected profit in order to receive a given level of profit in the future with certainty; (b) vegetable farmers are willing to pay more than cereal farmers in order to hedge against disastrous events. As already mentioned in the 'Estimation' sub-section of Section 4, these results indicate that these two crop groups are grown by different groups of farmers in our sample. Those farmers that grow cereals are hedging against the variability of their mean income, while those that grow vegetables are more sensitive to extreme events. Furthermore, the related risk premium (by unit of profit) associated to cereals is lower than its counterpart for the vegetable group. This could reflect a number of factors including self-selection of 
more risk averse farmers into the production of cereals, and more down-side risk averse farmers into the production of vegetables, on the basis of the associated distribution of profit. Such a configuration of risk preference might be explained by the fact that most cereal growers are full-time farmers, hence interested in sustaining a minimum income from farming, while most vegetable growers are part-time farmers, hence their mean income (from farming and non-farming activities) is significantly affected by changing weather conditions only in the occurrence of disastrous events. [Personal Communication: Prof. George Socratous, University of Cyprus]. It is more difficult to compare values of the relative risk premium on the basis of risk preferences alone, as the relative risk premia also depend on group-specific moments of the distribution of profit.

Given that the estimated system of equations in [5] are derived from the first order conditions for expected profit maximisation, theory suggests that the origin of the estimated equation should be equal to zero for each input (Antle 1987). Estimates of the constant term that are different from zero can be interpreted as a deviation from profit maximising choice of the particular input. We see from Table 2 that the estimate of the constant term is always significant, albeit close to zero for labour and water inputs. This suggests that, given the marginal cost, water and labour are being used efficiently by farmers in this region. However, the same cannot be said for fertilisers where positive and significant estimates for the constant terms are recorded for both crops. This implies that fertiliser is being overused by farmers in the production of both crops. ${ }^{\text {xvi }}$

The sensitivity of the moments of profit with respect to inputs are also of interest here. In general the three inputs have a positive impact upon expected profit, except fertiliser for cereals, but it is not significant (see Table 3). Only water and labour for vegetables are significant when explaining expected profit. Fertiliser is a variance increasing input in the production of both crops (although significantly so only for cereals) while water appears to be variance decreasing for vegetables but variance increasing for cereals. Labour is variance decreasing for both crop groups. These results concerning the variance of profit are consistent with the intuition (and earlier empirical work, see Antle 1987) that more labour generally helps reducing risk because problems associated with plant growth can be monitored more accurately, while overuse of fertiliser can increase production risk. Fertiliser and labour have a significant positive impact on profit skewness in the production of vegetables and cereals 
respectively. Table 3 shows clearly the benefits of employing the flexible approach of Antle in the estimation of agricultural production technology compared to that of, for example Just and Pope (1978, 1979). Whereas traditional estimation methods place constraints upon the impact of inputs on the moments of profit, the method employed here allows inputs to impact some moments of profit positively and others negatively. It seems clear that this is a more realistic representation of the production technology.

\section{[Table 3 here]}

\section{Analysis of the impact of water quotas}

In this section we illustrate the importance of estimating farmers' risk preferences for the economic evaluation of a water management policy: an unanticipated, exogenous quantity restriction or water quota. Quantity restrictions such as this are common water management instruments especially in the face of severe periodic water shortages and drought (Iglesias et al., 2003; Garrido et al., 2002; Moore and Negri, 1992). Given that irrigation water is derived from groundwater, one might ask how this policy exercise of water quotas could effectively be carried out. The difficulty of establishing and monitoring quotas in the context of commonpool groundwater extraction gives rise to the need for a tradable permit scheme (Provencher and Burt, 1993). In such a scheme, farms are granted an endowment of tradeable permits to the in situ groundwater stock, which they control over a specific time period. Each farm's bundle of permits represents its private stock of groundwater. This private stock declines due to groundwater pumping and increases to reflect the farm's share of periodic recharge. It also changes in response to the farm's activity in the market for groundwater stock permits, increasing when permits are purchased and decreasing when permits are sold. As a practical matter, the market price for permits serves to allocate groundwater over time. Our work in this paper indicates the importance of accounting for risk considerations when deciding the size of the endowment of tradable permits to the in situ groundwater stock. That is, this endowment should be a function, not only of the hydrogeological and climatic conditions that prevail in the region and farmers' production technology, but also the risk preferences of these farmers, which will define the way they use inputs in order to hedge against production risk.

\section{Scenarios}


In order to illustrate our point we consider three scenarios, which differ only in the information assumed available to the policy maker regarding farmers' risk preferences. We then go on to show how the evaluation of the policy differs across scenarios. In particular we evaluate three important dimensions of farmers' responses to restrictions in a risk averse environment: input mix, the moments of profit and average risk premiums. We assume that land (and other factors) is fixed and hence the response evaluated represents either a short-run response to a once and for all quantity restriction or the response to a one off water restriction in the face of a periodic water shortage.

In Scenario 1 we assume that the policy maker assesses the immediate impacts of the policy on the understanding that farmers are risk neutral and attempt to maximise expected profit. This represents perhaps the most usual way to handle conservation policies. In Scenarios 2 and 3 we assume that the policy maker is less naïve about risk preferences. In Scenario 2 farmers' preferences over the variance of profit are considered while in Scenario 3 it is assumed that preferences for both variance and skewness of profit are considered in evaluating the water management policy. That is, the policy maker considers both ArrowPratt $(A P)$ parameters in Scenario 2 and both $A P$ and down-side risk $(D S)$ aversion characteristics in Scenario 3. Scenario 3 allows us to illustrate the importance of preferences for higher order moments of profit in determining farmer responses. In evaluating the impact upon farmers of the water quota policy we calculate the elasticity with respect to water of the inputs to production for two crop groups: cereals and vegetables.

\section{Measurement of Farmer Responses}

Elasticities of inputs with respect to water are calculated from the system of first order conditions for expected profit maximisation, evaluated using the previously-obtained parameter estimates. Direct application of the general implicit function theorem yields:

$$
\begin{aligned}
& \frac{\partial F}{\partial W}=\frac{\partial^{2} \mu_{1} / \partial F \partial W-(A P / 2) \partial^{2} \mu_{2} / \partial F \partial W+(D S / 6) \partial^{2} \mu_{3} / \partial F \partial W}{\partial^{2} \mu_{1} / \partial F^{2}-(A P / 2) \partial^{2} \mu_{2} / \partial F^{2}+(D S / 6) \partial^{2} \mu_{3} / \partial F^{2}} \\
& \frac{\partial L}{\partial W}=\frac{\partial^{2} \mu_{1} / \partial L \partial W-(A P / 2) \partial^{2} \mu_{2} / \partial L \partial W+(D S / 6) \partial^{2} \mu_{3} / \partial L \partial W}{\partial^{2} \mu_{1} / \partial L^{2}-(A P / 2) \partial^{2} \mu_{2} / \partial L^{2}+(D S / 6) \partial^{2} \mu_{3} / \partial L^{2}} .
\end{aligned}
$$


In Scenario 1 ('Risk Neutrality'), equation [9] is evaluated assuming that $A P$ and $D S$ are equal to zero. Scenario 2 ('No down-side Risk') assumes that only DS is equal to zero and employs the estimated values for $A P$, whilst Scenario 3 employs the estimates of both $A P$ and $D S$ reported in the previous section. Using the comparative statics in [9] means that in each case and for each crop, elasticities of fertiliser and labour are assessed after water use, fertiliser and labour have responded. ${ }^{\text {xvii }}$ The results to this analysis are shown in Table 4. Note that, because the DS parameter is not significant for cereals, results are the same for Scenarios 2 and 3 concerning this group.

\section{[Table 4 here]}

The impacts of a water conservation policy can be interpreted as follows. In Scenario 1 the policy maker would expect cereal growers to increase fertiliser use by $0.29 \%$ and labour by $0.60 \%$ in response to a $1 \%$ restriction in water use. Once $A P$ characteristics are introduced in Scenario 2 the policy maker would expect a $0.52 \%$ increase for fertiliser and $0.22 \%$ for labour ; the sophisticated policy maker who takes into account preferences for higher order moments of profit would expect the same input variations, as $D S$ is not significant for cereals. These estimates are statistically significant predicted responses for risk neutrality regarding fertiliser, and full preferences regarding labour. The differences between the scenarios are clear. The naïve policy maker who assumes risk neutrality would underestimate (resp. overestimate) the response of farmers in choosing their substitute fertiliser (resp. labour) inputs.

In the case of vegetables, the difference between the naïve and the sophisticated policy maker is even more pronounced. The naïve policy maker in Scenario 1 would expect a significant and negative response $(-0.17 \%)$ in fertiliser applications, and a significant and positive response $(0.38 \%)$ for labour by farmers. On the contrary, the sophisticated policy maker in Scenario 3 would expect a significant and positive response $(0.11 \%)$ in fertilizer applications, and a significant and negative response (-0.33\%) for labour by farmers. Clearly, the sophisticated policy maker sees that water and fertiliser (resp. labour) are substitute (resp. complementary) inputs in the production of vegetables, whereas the naïve policy maker of Scenario 1 would, if anything, expect these inputs to be complementary (resp. substitute). 
This represents an important reflection of the importance of risk preferences in determining production decisions and evaluating policy responses.

The substantive differences between the scenarios analysed here come from the fact that under risk-neutrality reallocation of inputs is only determined by technological constraints, whereas under risk-aversion farmers reallocate inputs by considering not only technological issues but also risk hedging. A policy maker that ignores the latter elements of farmer decision-making will obtain a limited and potentially false prediction of the impacts upon farmers of water management policies. In the results above this is reflected in the different signs for input responses and the welfare effects reflected in the risk premium. As a result water managers will come to erroneous conclusions with regard to the optimal response to drought on the one hand and the optimal package of assistance or compensation to farmers in the face of constraints on the other. More generally, policy makers may fail to correctly predict the external effects if they are naïve to risk preferences. It is easy to imagine a scenario in which water restrictions lead to an increase in e.g. pesticide and fertiliser use, which in turn leads to a decline in water quality, where a naïve policy maker would expect the opposite response. The results in Table 4 alert our attention to this possibility in the case of fertilisers in Cyprus.

\section{Conclusion and suggestions for further research}

This paper contributes to the analysis of drought management polices in irrigated agriculture by illustrating the importance of estimating the risk preferences in evaluating their impact. Using data from the arid Kiti region of Cyprus we first estimate farmers' risk preferences using Antle's $(1987,1983)$ flexible method of moments approach. This reveals sensitivity of preferences to variance and, importantly, higher order moments of profit. We then analyse a drought management policy commonly applied in irrigation: a water quota restriction, from the perspective of three hypothetical water policy-makers who differ only in their understanding of farmers' risk preferences. We show that a naïve policy-maker, who believes farmers are risk neutral, can wrongly predict the direction of input responses and hence welfare changes by ignoring preferences over higher order moments of profit. This leads to the possibility of badly designed drought management policy: the quota restriction and/or compensation measures may be too lenient, severe or missing important dimensions such as 
insurance. Our analysis of a temporary water restriction represents the first step towards more comprehensive analyses of the response of risk averse farmers to water conservation policies. On the whole, this paper aims to draw policy-makers' attention to the fact that although under risk-neutrality reallocation of inputs is only determined by technological constraints, under risk-aversion farmers reallocate inputs by considering not only technological issues but also risk hedging. Hence, in the face of resource scarcity and uncertain resource availability, policy makers should design conservation policies and packages of technical assistance or compensation to farmers, by taking into account the effects of the farmers' risk preferences on production decisions. Ignoring these effects can lead to wrong evaluation of policy-responses. These results are relevant for the regulation of productive activities that are affected by exogenous stochastic events, in general. 


\section{References}

Agricultural Research Institute (1998) Norm Input-Output Data for the Main Crop and Livestock Enterprises of Cyprus, Agricultural Economics Report 36, Ministry of Agriculture, Natural Resources and the Environment, Cyprus.

Antle, J. (1983) Testing the Stochastic Structure of Production: A Flexible Moment-Based Approach, Journal of Business and Economic Statistics, 1, 192-201.

Antle, J. (1987) Econometric Estimation of Producers' Risk Attitudes, American Journal of Agricultural Economics, 69, 509-522.

Grigg,. N.S. (1996) Water resources management. Principles, regulations and cases, MacGraw-Hill, New York.

Iglesias, E., Garrido, A. and A. Gomez-Ramos (2003) Evaluation of Drought Management in Irrigated Areas, Agricultural Economics, 29, 211-229.

Just, R. and R. Pope (1978) Stochastic Representation of Production Functions and Econometric Implications, Journal of Econometrics, 7, 67-86.

Just, R. and R. Pope (1979) Production Function Estimation and Related Risk Considerations, American Journal of Agricultural Economics, 61, 276-284.

Keplinger, K., B. A. McCarl, M. Chowdhury, and R. Lacewell. (1998). Economic and Hydrologic Implications of Suspending Irrigation in Dry Years. Journal of Agricultural and Resource Economics, 23:191-205.

Koundouri, P. (2000) Three Approaches to Measuring Natural Resource Scarcity: Theory and Application to Groundwater. Ph.D. Thesis, Faculty of Economics and Politics, University of Cambridge. 
Koundouri, P., Nauges, C. and Tzouvelekas,. V. (2005) Endogenous Technology Adoption Under Production Risk: Theory and Application to Irrigation Technology, American Journal of Agricultural Economics, forthcoming.

Kumbhakar, S.C. (2002) Specification and Estimation of Production Risk, Risk Preferences and Technical Efficiency, American Journal of Agricultural Economics, 84, 8-22.

Kumbhakar, S.C., and R. Tveterås (2003) Risk Preferences, Production Risk and Firm Heterogeneity, Scandinavian Journal of Economics, 105(2), 275-293.

Leathers, H.D. and Quiggin J.C. (1991) Interaction between Agricultural and Resource Policy: The Importance of Attitudes toward Risk, American Journal of Agricultural Economics, 73, 758-764.

Love, H.A. and S.T. Buccola (1991) Joint Risk Preference-Technology Estimation with a Primal System, American Journal of Agricultural Economics, 73, 765-774.

Love, H.A. and S.T. Buccola (1999) Joint Risk Preference-Technology Estimation with a Primal System: Reply, American Journal of Agricultural Economics, 81, 245-247.

Massachusetts Institute of Technology (1999) Solutions to Water Scarcity in the Republic of Cyprus. A Proposal for Water Banking, The Massachusetts Institute of Technology Water Resources Group.

Menezes, C., Geiss, C. and J. Tressler (1980) Increasing Down-side Risk, American Economic Review, 70, 921-932.

Miyata, S (2003) Household's risk attitudes in Indonesian villages, Applied Economics, 35(5), 573-583.

Moore, M., N. Gollehon and M. Carey (1994) Multicrop Production Decisions in Western Irrigated Agriculture: The Role of Water Price, American Journal of Agricultural Economics, 76, 859-874. 
Moore, M. and D. Negri (1992) A Multicrop Production Model of Irrigated Agriculture, Applied to Water Allocation Policy of the Bureau of Reclamation, Journal of Agricultural and Resource Economics, 17, 29-43.

Nieswiadomy, M (1988) Input Substitution in Irrigated Agriculture in the High Plains of Texas, 1970-80, Western Journal of Agricultural Economics, 13, 63-70.

Ozanne, A (1998) Uncertainty, Duality and Perversity: an empirical test of the Schultz-Baron hypothesis, Applied Economics, 30(4), 521-530.

Pope, R. (1982) Empirical Estimation and Use of Risk Preference: An Appraisal of Estimation Methods That Use Actual Economic Decisions, American Journal of Agricultural Economics, 64, 376-383.

Provencher, B. and O. Burt (1993) The externalities associated with the common property exploitation of groundwater, Journal of Environmental Economics and Management, 24, 13958.

Schaible, G. (1997) Water Conservation Policy Analysis: an interregional, multi-output primal-dual optimisation approach, American Journal of Agricultural Economics, 75, 163175.

Socratous, G. (2000) Water Pricing in Cyprus. Paper Presented at the Water Resources Management Symposium, Sept 2000, Nicosia, Cyprus.

Stiglitz, J. (1974) Incentives and Risk Sharing in Sharecropping, Review of Economic Studies, 41, 219-255.

Wik M., Kebede T. A., Bergland O., and S.T. Holden (2004) On the measurement of risk aversion from experimental data, Applied Economics, 36(21), 2443-2451. 
Table 1. Descriptive statistics by crop group

\begin{tabular}{|c|c|c|c|c|}
\hline & \multicolumn{2}{|c|}{ VEGETABLES } & \multicolumn{2}{|c|}{ CEREALS } \\
\hline & Mean & St Dev. & Mean & St Dev. \\
\hline Surface allocated ${ }^{1}$ (ha) & 2.87 & 5.79 & 2.79 & 4.11 \\
\hline Gross revenue/ha (CYP/year) ${ }^{2}$ & 2614.91 & 4079.79 & 628.33 & 1138.26 \\
\hline Fertiliser expenditures ${ }^{3}$ (CYP/ha/year) & 201.53 & 395.50 & 85.43 & 274.56 \\
\hline Water expenditures (CYP/ha/year) & 359.66 & 359.00 & 104.23 & 211.34 \\
\hline Labour expenditures (CYP/ha/year) & 662.38 & 2147.58 & 589.35 & 2075.12 \\
\hline WELLON (1= well on parcel) & 0.4592 & 0.5001 & 0.39 & 0.49 \\
\hline DIST1 (distance to nearest town, in km) & 11.43 & 6.80 & 9.91 & 5.24 \\
\hline DIST5 (distance to nearest river, in km) & 2.07 & 2.97 & 2.15 & 1.54 \\
\hline RESERVOIR (1= access to water reservoir) & 0.2370 & 0.4268 & 0.1804 & 0.38 \\
\hline LAND (1= parcel belongs to agricultural zone) & 0.7926 & 0.4069 & 0.8295 & 0.39 \\
\hline Number of observations & & & & \\
\hline
\end{tabular}

\footnotetext{
${ }^{\mathrm{I}}$ includes irrigated and not irrigated area.

${ }^{2}$ CYP: Cyprus pound (1 CYP was US\$1.5 in 1998).

${ }^{3}$ including manure.
} 
Table 2. Estimation results

\begin{tabular}{lrr}
\hline Parameter & Cereals & Vegetables \\
\hline$\theta_{1 F}$ (fertiliser intercept) & $-0.0540^{* * *}$ & $0.0619^{* * *}$ \\
& $(-3.48)$ & $(31.63)$ \\
$\theta_{1 W}$ (water intercept) & $0.0011^{* * *}$ & $0.0000^{* * *}$ \\
& $(15.58)$ & $(2.82)$ \\
$\theta_{1 L}$ (labour intercept) & $0.0035^{* * *}$ & $0.0011^{* * *}$ \\
& $(8.58)$ & $(9.52)$ \\
$A P$ & $0.3401^{* *}$ & $0.0726^{* * *}$ \\
& $(2.61)$ & $(2.97)$ \\
$D S$ & -0.0884 & $0.2930^{* * *}$ \\
& $(-0.61)$ & $(35.90)$ \\
\hline Observations & 135 & 133 \\
Wald test for equality between AP and DS : $\chi^{2}(2)=264.98(0.0000)$ & 0.2216 \\
Relative Risk Premium & 0.1708 & \\
$(R P / E \Pi)$ & & \\
\hline
\end{tabular}

Estimation method: 2SLS. Instruments used: (WELLON, DIST1, DIST5, RESERVOIR, LAND). $t$-ratio (Student) statistics are in parentheses, except $p$-value for the Wald test. ***,** and * denote significance at 1,5 and 10 percent respectively. AP and DS denote Arrow-Pratt and down-side risk coefficients respectively. 
Table 3. Sensitivity of the distribution of profit with respect to inputs

\begin{tabular}{lcccr}
\hline & Cereals & & \multicolumn{2}{c}{ Vegetables } \\
Parameter & Mean & Std. Error & Mean & Std. Error \\
\hline$\partial E(\Pi) / \partial F$ & -0.0344 & 0.0689 & $0.0493^{*}$ & 0.0278 \\
$\partial E(\Pi) / \partial W$ & 0.0035 & 0.0072 & $0.0002^{* *}$ & 0.0001 \\
$\partial E(\Pi) / \partial L$ & 0.0180 & 0.0864 & 0.0021 & 0.0028 \\
$\partial \operatorname{Var}(\Pi) / \partial F$ & $0.1293^{*}$ & 0.0687 & 0.1367 & 0.0969 \\
$\partial \operatorname{Var}(\Pi) / \partial W$ & 0.0114 & 0.0301 & -0.0004 & 0.0004 \\
$\partial \operatorname{Var}(\Pi) / \partial L$ & -0.0070 & 0.0113 & -0.0015 & 0.0040 \\
$\partial S k(\Pi) / \partial F$ & -0.2788 & 0.2539 & $0.3547^{* *}$ & 0.1546 \\
$\partial S k(\Pi) / \partial W$ & 0.0335 & 0.0818 & -0.0002 & 0.0008 \\
$\partial S k(\Pi) / \partial L$ & $0.1864^{* * *}$ & 0.0696 & -0.0219 & 0.0437 \\
\hline
\end{tabular}

Notes. $\Pi$ is profit, $F, W$ and $L$ are respectively fertiliser, water and labour inputs, Var and $S k$ denote the second moment (variance) and third moment (skewness), respectively. $* * *, * *$ and $*$ denote significance at 1,5 and 10 percent respectively. 
Table 4. Water quota policy simulation - Input elasticities (for a 1\% decrease in water use)

\begin{tabular}{rrr}
\hline \multicolumn{3}{c}{ Cereals - Elasticity of Fertiliser and Labour to Water } \\
& Fertiliser / Water & Labour / Water \\
\hline $\begin{array}{r}\text { Risk Neutrality } \\
(A P=D S=0)\end{array}$ & $0.2984^{* * *}(0.1016)$ & $0.6018(0.4262)$
\end{tabular}

No down-side Risk

$$
(D S=0)
$$

$0.5180(0.3621)$

$0.2275 * * *(0.0749)$

Full Risk Preferences

$0.5180(0.3621)$

$0.2275 * * *(0.0749)$

Vegetables - Elasticity of Fertiliser and Labour to Water

Fertiliser / Water

Labour / Water

Risk Neutrality

$(A P=D S=0)$

$-0.1708^{* * *}(0.0434)$

$0.3812 * * *(0.0683)$

No down-side Risk

$$
(D S=0)
$$

$$
-0.7241^{* * *}(0.0442)
$$

$0.1101 *(0.0645)$

Full Risk Preferences

$$
0.1093 *(0.0641)
$$

$-0.3374 * *(0.1696)$

Notes: Standard errors are in parentheses. ${ }^{* * *},{ }^{* *}$ and $*$ denote significance at the $1 \%, 5 \%$ and $10 \%$ level respectively. Reported estimates correspond to a 1 percent decrease in the water input. 


\section{Endnotes}

${ }^{\mathrm{i}}$ Ozanne (1998) provides evidence of the importance of risk preferences for policy analysis in agriculture.

ii Such an approach goes as far back as Stiglitz (1974).

iii See for example, Pope (1982).

iv This assumption is not critical as long as farmers are price-takers. Extending the model by allowing for price risk in addition to production risk, although feasible, would not bring about significant changes in the analysis.

${ }^{v} \bar{X}_{w}$ is either in absolute or relative terms. In the latter case, we would have for example $\bar{X}_{w}=(1-\delta) X_{w}^{0}$, with $X_{w}^{0}$ the reference water consumption, and $\delta$ the desired rate of reduction in water use.

${ }^{\text {vi }}$ With the multiplicative risk specification that we have here, $\varepsilon$ could also represent output price risk, $p$. However, we wish to focus on climate as the particular source of uncertainty. vii The inclusion of a constant term in the empirical model measures the extent to which the population exhibits profit maximising behaviour. Theory suggests that for profit maximising farmers this should be zero and hence in the results section we check this hypothesis for each model.

viii Down-side risk is concerned with asymmetric (skewed) statistical distributions of profit and in particular aversion to disastrous events (see e.g., Menezes et al., 1980 for a discussion). ${ }^{\text {ix }}$ A comparison to national statistics (see Agricultural Research Institute, 1998) reveals that the Kiti region provides a reasonable representation of the composition of crop production in Cyprus as a whole.

${ }^{\mathrm{x}}$ Major crops in the region are coriander and broad bean (respectively $13.5 \%$ and $16.5 \%$ of total area), barley and wheat (respectively $18.9 \%$ and $14.6 \%$ of total area).

${ }^{\mathrm{xi}}$ Citrus is also grown in the Kiti area however the data for this production were too sparse for the estimation of risk parameters.

xii Water requirements range from $2200 \mathrm{m3} / \mathrm{ha} /$ year for broad bean, to $6800 \mathrm{m3} / \mathrm{ha} /$ year for okra. Concerning cereals, these requirements are respectively $5500 \mathrm{~m} 3 / \mathrm{ha} /$ year for bran, barley and wheat, and $6500 \mathrm{~m} 3 / \mathrm{ha} /$ year for corn.

xiii Irrigation water costs depend on an area-specific pumping lift, ranging between 6.5 and 18.5 meter. Marginal groundwater costs are estimated between $0.13 \mathrm{CYP} / \mathrm{m} 3$ and 0.37 $\mathrm{CYP} / \mathrm{m} 3$, depending on the area (Koundouri, 2000). 


\begin{abstract}
${ }^{\text {xiv }}$ All variables are rescaled by their standard deviation.
${ }^{\mathrm{xv}}$ The $4^{\text {th }}$ moment, kurtosis, was also considered however, estimated coefficients were not significant. We concentrate on variance and skewness in order to illustrate the importance of higher order moments to farmers' decisions.

${ }^{x v i}$ However, this could be some remnant of the composite nature of the fertilizer input.

${ }^{\text {xvii }}$ Given our assumption that land (and other factors), output and input prices are assumed fixed, it is unrealistic to draw inferences from a simulation scenario that results in input values very far from reference values. Presumably, if the quota policy requires large variations in water use from the reference case, farmers are likely to react, not only by adjusting the levels of their other inputs, but also by curtailing production on certain areas of land, possibly also modifying prices.
\end{abstract}




\title{
Replies to the referee on « The story of the moment: risk averse Cypriot farmers respond to drought management "
}

\begin{abstract}
We wish to thank the referee for his relevant comments and useful suggestions. We explain below how we responded to each of the critics.
\end{abstract}

\section{Comments 1 and 2) Specification of the production function.}

The authors collectively agree with the referee's critic about the omission of labour in the production function. We thus followed the referee's suggestion by considering labour as an additional variable input in the production function, in addition to fertilizer and water. Land is still assumed to be a fixed factor. Basic statistics on the three variable inputs are shown in Table 1.

\section{Comment 3) Choice of the quadratic functional form.}

The quadratic functional form (which is commonly used in the estimation of agricultural profit functions) has been chosen because it is flexible in the sense of a second-order approximation of any unknown profit function (Kumbhakar and Tveterås, 2003). Although other flexible forms are considered in the literature, such as the Translog specification in particular, preliminary estimates revealed that the quadratic profit function performed better in terms of statistical fit on our sample. We justify our choice of a quadratic functional form, along these lines, in the revised version of the article (page 11).

\section{Comment 4) Choice of GMM as an estimation technique.}

Following the referee's comment, we decided to estimate the model using a Two Stage Least Squares (2SLS) estimation technique, instead of a GMM. The major difference in our (linear) case between 2SLS and GMM would be in terms of robustness with respect to error variance misspecification, the 2SLS estimator being however more efficient under the assumption of homoskedasticity. Instruments are: WELLON, a dummy variable which takes the value of 1 if there is a well in the parcel and zero otherwise, DIST1: distance of the parcel to the nearest town (in $\mathrm{km}$ ), DIST5: distance of the parcel to the nearest river (in $\mathrm{km}$ ), RESERVOIR, a dummy variable which takes the value of 1 if the farmer has access to a water reservoir and 
zero otherwise, LAND, a dummy variable which takes the value of 1 if the parcel belongs to an agricultural zone and zero otherwise.

\section{Comment 5) Definition of variables.}

In the revised version of the article, we define precisely all the variables, including instruments, and show corresponding descriptive statistics in Table 1.

\section{Comment 6) Better explain differences between results for vegetables and cereals.}

We describe the differences in terms of estimated risk aversion parameters (between the two groups of farmers) in greater details, and we provide some explanations for these differences. We argue that "such a configuration of risk preference might be explained by the fact that most cereal growers are full-time farmers, hence interested in sustaining a minimum income from farming, while most vegetable growers are part-time farmers, hence their mean income (from farming and non-farming activities) is significantly affected by changing weather conditions only in the occurrence of disastrous events. [Personal Communication: Prof. George Socratous, University of Cyprus].” This discussion is found on pages 12-13 in the revised version of the paper.

\section{Comment 7) Testing of underlying assumptions.}

The statistical significance of the risk parameters (Arrow-Pratt and Down-side risk parameters) is an indirect test of the following joint hypotheses: a) underlying production risk is affected by input choices by the farmer; b) producers care about production risk, i.e., they are not risk neutral.

\section{Comment 8) Conclusion.}

We have tried to add more elements in the conclusion, in particular to emphasize more the implications of our results for policy makers. We argue that, "on the whole, this paper aims to draw policy-makers' attention to the fact that although under risk-neutrality reallocation of inputs is only determined by technological constraints, under risk-aversion farmers reallocate inputs by considering not only technological issues but also risk hedging. Hence, in the face of resource scarcity and uncertain resource availability, policy makers should design conservation policies and packages of technical assistance or compensation to farmers, by taking into account the effects of the farmers' risk preferences on production decisions. Ignoring these effects can lead to wrong evaluation of policy-responses. These results are 
relevant for the regulation of productive activities that are affected by exogenous stochastic events, in general.” This discussion can be found on pages 17-18 of the revised article.

\section{Comment 9) Presentation of the results in Table 2.}

We improved the presentation of the results in Table 2. In particular, in the revised version of the paper, we explain that the parameter $\theta_{1 k}$ is the intercept in the first order condition (derived from the maximisation of farmer's expected utility of profit) for input $k$ ( $k=$ fertilisers, water, labour). AP and DS, which represent the Arrow Pratt and down-side risk aversion parameters respectively, are now described in the note at the bottom of Table 2 . The Hansen test no longer appears in the table, as we no longer use GMM (the Hansen test was used in the previous version of the paper, to test for the validity of the moment conditions).

We believe that these revisions address the concerns expressed and the points of clarification; however, if you should require any further explanation from us with regard to these points, please do not hesitate to contact us. 